\title{
A RESOLUÇÃO E EXPLORAÇÁO DE PROBLEMA À EDUCAÇÃO E À DIVERSIDADE PRISIONAIS
}

THE RESOLUTION AND EXPLORATION OF PROEDUCANDOSBLEM TO PRISON EDUCATION

AND DIVERSITY

\author{
Miguel de Brito Santos \\ Mestre em Educação Matemática - UEPB \\ Técnico em Assuntos Educacionais \\ miguelbrisan@hotmail.com
}

\section{RESUMO}

O artigo ora apresentado é resultado da releitura do capítulo três da pesquisa desenvolvida com educandos privados de liberdade, experiência que aproximou, em seu tempo, a educação matemática desenvolvida pela Universidade Estadual da Paraíba - UEPB, à educação prisional, tendo como elo a pesquisa narrativa. Assim, foi possível aproximar experiências profissionais à metodologia exploraçáo-resolução de problema em condiçóes de privação de liberdade. A resolução-exploração de problema enquanto metodologia se apresenta como forte base ao educador que trabalha naquela condição. Além disso, a pesquisa revelou aproximaçóes com outras áreas do conhecimento de tal modo a fortalecer argumentaçóes, mesmo que em área aparentemente distante como é o caso do Direito. Emergem possibilidades de fundamentar, com base em campos da educação matemática, estudos voltados às populaçóes de assistidos. Olhamos, mesmo que de modo tangencial, constructos da educação em presídios, o direito à educação, previsto internacionalmente, além de elementos quantitativos que apontam a dimensão do problema, por exemplo, a população brasileira analfabeta fora e dentro dos presídios.

Palavras-chave: Educação. Matemática. Presídio. Problema. Narrativa. 


\section{ABSTRACT}

The article presented is the result of the re-reading of chapter three of the research developed with students deprived of liberty, an experience that approached, in its time, the mathematical education developed by the State University of Paraíba (UEPB) to prison education, its link was Narrative research. Therefore, it was possible to approach experienced professionals to the exploratory-problem solving while methodology itself conditions of prisoners deprivation of liberty. The resolution-exploration of problem as methodology presents as a strong basis to the educator working in that condition. Besides that, the research revealed approximations with other areas of knowledge in such a way as to strengthen arguments, even in a seemingly distant area such as Law. There are possibilities to base, based on fields of mathematical education, studies aimed at the populations of assisted. Although tangential, we might have been noted, constructs of education in prisons, the right to education, predicted internationally, in addition to quantitative elements that point out the scale of the problem, for example, the Brazilian population illiterate outside and inside the prisons.

Keywords: Education. Mathematics. Prison. Problem. Narrative.

Data de submissão: 20/03/2017

Data de aceitação: 18/08/2017

\section{SUMÁRIO}

INTRODUÇÃO 1. A DECISÃO PELA SALA DE AULA COM EDUCANDOS PRIVADOS DE LIBERDADE 2. OS DIFERENTES DOMÍNIOS DE EXPERIÊNCIAS PROFISSIONAIS ASSOCIADOS AO MODELO DE ENTRADA E A RESOLUÇÃO-EXPLORAÇÁO DE PROBLEMA 3. APROXIMAÇÓES DA NARRATIVA EM EDUCAÇÃO MATEMÁTICA ÀS REFERÊNCIAS EM DIREITO E EDUCAÇÃO EM PRESÍDIOS. CONSIDERAÇÓES FINAIS. 


\section{INTRODUÇÁO}

Oartigo apresentadoaseguirépartedapesquisa, narrativa, educação matemáticacomeducandosprivadosdeliberdade:um trabalhocomametodologiaexploração-resoluçãodeproblemas.

Durante a escrita desse artigo, tomamos como base o capítulo três da pesquisa desenvolvida em sala de aula com educandos privados de liberdade. Apresentamos, assim, as etapas como o capítulo foi se constituindo. Primeiro encontramos algumas referências da área de educação prisional. Mostraremos adiante, em pesquisas específicas do campo de educação em presídios, publicadas pelo INEP - Instituto de Estudos e Pesquisas Educacionais, que se associaram a referências desenvolvidas pela própria Defensoria Pública da União por meio da Revista da Defensoria Pública da Uniáo e da cartilha de orientaçóes jurídicas, ambas as publicaçóes distribuídas nacionalmente. Essa última, embora seja uma referência de orientaçóes básicas aos assistidos, mostrou-se, visualmente, com forte poder de síntese ao identificar por meio da figura: o homem do campo, o aposentado, o enfermo, o preso. O formato de uma simples cartilha se aproximou, ao nosso olhar em pesquisa, de discussóes e palestras que abordavam o perfil da população carcerária brasileira. A partir de percepções emergidas do trabalho cotidiano, encontramos, também, na Revista da Defensoria Pública da União uma fonte que subsidiou questôes relativas à área do Direito. Destacamos aqui a necessidade de uma breve aproximaçẫo, como mostraremos, com aquela área.

Em um segundo momento, aproximamos experiências acadêmicas às vividas no Instituto Nacional de Estudos e Pesquisas Educacionais Anísio Teixeira (INEP) e na Defensoria Pública da União (DPU). Pois, ao olhar os assistidos sob o ponto de vista educativo, vimos a educação de jovens e adultos, contudo, em uma escola com educados privados de liberdade.

Pensamos, inicialmente, em desenvolver a pesquisa com os itens do Exame Nacional do Ensino Médio (ENEM) em uma escola regular que não um presídio. Contudo, o cotidiano do trabalho na DPU nos levou à experiência em sala de aula prisional.

Então, desenvolvemos, tendo como foco a metodologia resoluçáo-exploração de problema, por meio da pesquisa narrativa à aproximação de cotidianos da academia, profissional e do presídio. 
Isso foi possível porque pensamos em um modelo, apresentado no capítulo quatro da pesquisa, e que aqui retomamos, em tópico a seguir, enquanto suporte aos deslocamentos entre domínios, condição que contribuiu com a aplicação da metodologia utilizada em sala de aula.

Precisamos olhar a educação em prisóes de modo a conceber o contexto da pesquisa como parte de um processo global mais amplo. Assim, narramos, com base em referências da área de educação em presídios, atividades (seminários e discussões com foco em educação prisional) que permitiram um olhar panorâmico da educação prisional.

\section{A DECISÁO PELA SALA DE AULA COM EDUCANDOS PRIVAdOS DE LIBERDADE}

$\mathrm{O}$ interesse pela pesquisa em sala de aula prisional ocorreu, inicialmente, quando encontramos a revista Em Aberto. ${ }^{1}$ Sobretudo porque vimos a possibilidade de aproximar experiências de diferentes cotidianos.

A narrativa, enquanto elemento de aproximação da vida acadêmica ao trabalho e ao domínio prisional, apareceu nas primeiras aulas na universidade quando encontramos a linha de pesquisa narrativa. Por outro lado, no artigo "Educação Escolar na Prisão: controvérsias e caminhos de enfrentamento e superação da cilada" ${ }^{2}$, vimos a narrativa base de análise do panorama latino-americano, particularizando a educação em espaço de privação de liberdade:

As interpretações sobre a América Latina são múltiplas, podendo ser distintas, complementares e ao mesmo tempo divergentes. Sob esse aspecto, pode ser vista como figuras e figuraçóes de uma longa narrativa, permeada por construçóes intelectuais, que distinguem e mesclam, recriam-se e transfiguram-se, uma vez que o mesmo pensamento que descreve, compreende, explica ou nomeia, participa decisivamente da constituiçấo do objeto, seja este coisa, gente ou ideia. ${ }^{3}$

Os dois parágrafos acima indicam momentos de contatos com leituras aparentemente

EM ABERTO é uma publicação monotemática do Instituto Nacional de Estudos e Pesquisas Educacionais Anísio Teixeira (INEP).

2 ONOFRE, E. M. C. Educação escolar na prisão: Controvérsias e caminhos de enfrentamento e superação da cilada. In: LOURENÇO, A. S. da. e ONOFRE, E. M. C. (Orgs). O espaço da prisáo e suas práticas educativas: enfoques e perspectivas contemporâneas, 2012.

3 op. Cit. p. 267-268 
distantes da educação matemática, desse modo percebemos a necessidade de situar essas leituras, inicialmente, antes de apresentar as aproximaçóes entre o trabalho na defensoria, a experiência em sala de aula e a metodologia resolução-exploração de problema aplicada. Além disso, uma vez que a Defensoria Pública atua com a diversidade brasileira, há possibilidade de se olhar essas populaçóes mediante um programa etnomatemático que considere a diversidade étnica de populaçóes assistidas pelo órgão.

A Defensoria atua diante da própria diversidade brasileira. Como forma de simplificar visualmente a abrangência da área de atuação desse órgão público, selecionamos a imagem da Cartilha de Orientaçáo Jurídica. Nela é possível identificar o homem do campo, o aposentado, o enfermo, a mulher, o preso, o deficiente nas mais diversas formas de deficiência, o aposentado. A cartilha é uma fonte em que se vê o amplo espectro de atuação da Defensoria Pública da União.

Extraímos um pequeno trecho da cartilha em que o papel da DPU é apresentado de modo panorâmico:

A Defensoria Pública da União (DPU) existe para dar assistência jurídica gratuita à população carente. Ou seja, é a instituição que defende os direitos, na justiça ou fora dela, de quem náo tem condiçóes de pagar por um advogado particular. Náo se paga nada para ser atendido. ${ }^{4}$

A imagem simbólica, figura, fortaleceu a perspectiva de aproximar educação de jovens e adultos às atividades do cotidiano e isso inserido em uma pesquisa.

Outro elemento de partida foram as publicaçóes anuais da Revista da Defensoria Pública e os recortes, citados a seguir, que contribuem com o entendimento, embora panorâmico, do papel da Defensoria Pública da União.

Vejamos. No artigo de Daniel Mourges Cogoy, a Defensoria é vista no momento de sua inserção na constituiçẫo de 1988:

No Brasil, a assistência jurídica aos pobres é garantida desde a Constituição de 1934. Esta previa, em seu artigo 113, que cabia ao estado prestar assistência jurídica aos necessitados. Apenas na Carta Magna de 1988, porém, em seu artigo 134, foi criada a Defensoria Pública

4 DEFENSORIA PÚBLICA DA UNIÃO. Direitos previdenciários e assistências. Cartilha de orientaçáo jurídica, 2014, p. 7. 
como instituição - no âmbito estadual e federal - com a finalidade de garantir assistência jurídica gratuita a todos os necessitados (...). Primeiramente, na esfera criminal, visando garantir o direito de defesa e contraditório aos acusados em geral, especialmente os pobres. E, mais recentemente, ampliando sua esfera de atuação, a fim de garantir também a esfera cível, com ênfase na tutela de direitos da família e direitos possessórios, para, a pouco tempo, abranger outras áreas, como a defesa do consumidor e mesmo a tutela de direitos difusos e coletivos. ${ }^{5}$

Na edição de 2013, Erik Palácio Boson diz sobre a Defensoria Pública:

Por expressa determinação constitucional, a Defensoria Pública da União é instituição permanente e essencial à função jurisdicional do estado. A ela incumbe, como expressão e instrumento do regime democrático, a orientaçáo jurídica, a promoção dos direitos humanos e a defesa dos direitos e a defesa dos direitos individuais e coletivos, de forma integral e gratuita, aos necessitados. ${ }^{6}$

Em outro momento, o autor destaca a defesa dos direitos individuais e coletivos de grupos sociais, vulnerável ou não economicamente, para isso considera construtos que abordam o conceito de grupos sociais, como é o caso de Gisele Aparecida dos Santos ao dizer:

Os grupos sociais incluem, mas não se limitam a grupos culturais. Entre os grupos sociais, estariam aqueles baseados no gênero, raça e etnicidades (além de cultura e religião). O que os torna um grupo social é que formam suas identidades a partir de práticas comuns e do mesmo status social. A identidade é constituída com base na partilha de um destino comum. Um ponto fundamental para se entender a noção de grupo social é que sua identificação não é dada pela adoção, consciente, de práticas ou modo de agir, mas pelo modo como é visto pelos outros grupos sociais. ${ }^{7}$

As populações prisionais são formadas por toda essa diversidade. Em um momento particular de nossa pesquisa, foi possível perceber, de um lugar que não o de educador, a convivência entre apenados, professores e agentes penitenciários. Abaixo indicamos a passagem em que registramos um breve momento dessa convivência:

\footnotetext{
5 COGOY, D. M. Assistência jurídica e judiciária no Brasil: Legitimação, eficácia e desafios do modelo brasileiro. Revista da Defensoria Pública da Uniáo, 2012, p. 145-146.

6 BOSON, E. P. A Defensoria Pública como Instituição articuladora do direito como padrão de reconhecimento. Revista da Defensoria Pública da Uniáo, 2013, p.11-12.

7 SANTOS, G. A. As cotas como projeto de multiculturalismo. In: Reconhecimento, utopia, distopia: os sentidos das políticas das cotas raciais, 2012, p.2.
} 
Enquanto o professor apresentava os textos em espanhol, pedi licença para pegar a lista de presença. Um movimento bastante simples, pegar a lista de presença apenas. Porém, foi além desse entendimento. Porque com esse movimento me desloquei da condição de educador para a de observador. E foi aí que vi, pela primeira vez, um momento cotidiano do convívio de três "populações": os agentes, os apenados e os professores. Precisei desenhar, na máo esquerda, as letras AAP de apenados, agentes e professores, usei esse artifício consciente porque precisava lembrar o momento durante narrativa. ${ }^{8}$

Essas experiências durante a convivência com os apenados nos levaram a um esforço de síntese das unidades narrativas, onde procuramos condensar as percepçóes em dois planos: a) entrelinhas dos diálogos e b) o trabalho com a metodologia resolução-exploração de problema aplicada em sala de aula.

Dessa maneira, ampliando as experiências indicadas acima, retomamos esses dois planos com intuito de pontuar algo presente nas entrelinhas e que está relacionado à saúde mental das pessoas encarceradas. A seguir resgatamos, ao concluir a escrita das entrelinhas, dentre as possíveis doenças do domínio prisional a de pessoas com transtorno em conflito com a lei: "Concluindo esse primeiro plano, lembrei-me de evidências de possíveis quadros de educandos com transtornos mentais em conflito com a lei, contudo tais percepçóes ficaram encobertas." 9

Ao escrevermos evidências, queremos dizer que podemos localizar educandos com tais transtornos, já abordado, inclusive pelo Ministério da Saúde. Contudo, nessa pesquisa essa questáo ficou no que chamamos de entrelinhas. Poderíamos ter citado outra doença como a Síndrome da Imunodeficiência Adquirida (AIDS), mas no caso do transtorno, o adoecimento é proveniente do conflito:

Segundo o relatório do Conselho Nacional de Justiça (CNJ) (junho/2014), as quase três mil unidades prisionais brasileiras mantêm sob a custodia do Estado cerca de 700 mil pessoas, sendo 4500 pessoas com transtorno mental em conflito com a lei $(85 \%$ custodiadas em Hospitais de Custodia e Tratamento Psiquiátrico - HCTP - ou Alas Psiquiátricas e 15\% em unidades prisionais comuns). Esse número que nos últimos anos vem mostrando tendência de crescimento pode, no entanto, ser maior: se fossem realizadas avaliaçóes interdisciplinares integrais e todas as pessoas privadas de liberdade no sistema prisional, seguramente encontraríamos um numero signi-

$\overline{8}$ SANTOS, M. B. de. Educaçáo matemática com educandos privados de liberdade [manuscrito]: um trabalho com a metodologia resolução e exploração de problemas, 2016, p. 46.

9

op. cit, 142 . 
ficativo de pessoas com transtorno mentais necessitando de medidas terapêuticas, entre outros motivos, por uso abusivo de drogas, ou por agravos psicossociais decorrentes das condiçóes de confinamento e desassistência no cárcere ${ }^{10}$.

Destacamos esse caso particular de doenças que é o transtorno mental de pessoas em conflito com a lei porque evidencia o adoecimento humano na relação com o Estado. Procuramos, contudo, narrar diferentes momentos da convivência com educandos privados de liberdade. Pois, esses momentos compóem entrelinhas que procuramos capturar.

Identificamos, por exemplo, educandos que apresentam mais condições de leituras. $\mathrm{O}$ que podemos ver no diálogo, a seguir, quando um dos educandos se referiu à Bíblia, enquanto a lia:

$[\ldots]$

— Professor, sete é o número da perfeição?

Fiquei surpreso com a pergunta.

- Por que essa pergunta?

[...] A matemática começava a ser retomada. Então outra colocação apareceu com relação ao número sete $[\ldots]$.

- A Bíblia diz que tudo que Deus fez sempre foi em sete dias. A princípio Deus criou tudo em seis dias e no sétimo ele descansou. Então, sete é um número de plenitude, do tempo, do acabamento. Alguns dizem que o sete é o número da mentira, mas não é verdade.

Ficamos surpresos com algumas intervençóes. $\mathrm{O}$ diálogo acima mostra isso, porque os números primos apresentam suas particularidades: os conhecemos, podemos gerá-los, mas há sempre um próximo desconhecido. Esse fato indica que diferentes percepçóes de mundo, grupos sociais, convivendo em condiçóes de cerceamento de liberdade, podem construir outra visão mais rica e elaborada.

10 MINISTÉRIO DA SAÚDE. Serviço de Avaliação de Medidas Terapêuticas Aplicáveis à Pessoa com Transtorno Mental em Conflito com a Lei, 2014, p. 8. 
Ubiratan D'Ambrósio trata de diferentes visóes de mundo no artigo "A História da Matemática: questôes historiográficas e políticas e reflexos na educação matemática" ${ }^{11}$ ao dizer:

Por razôes várias, ainda pouco explicadas, a civilização ocidental, que resultou dessas culturas, veio a se impor a todo o planeta. Com ela, a Matemática cuja origem se traça às civilizaçóes mediterrâneas, particularmente à Grécia antiga, também se impôs a todo o mundo moderno. Populaçôes excluídas em consequência do processo colonial tentam, rapidamente, assimilar esse conhecimento. ${ }^{12}$

Essa percepção de processo histórico das relaçôes homem-homem e homem-natureza são essenciais ao fortalecimento de outras visões que não as de negação do próprio homem. E no quadro particular do domínio prisional, em uma sociedade massificada, o homem é a massa, o encarceramento é de massas de populações que trazem em sua própria história as marcas de opressão. Com esse pensamento, a metodologia resolução-exploração aplicada pode receber, acreditamos nessa possibilidade, contribuição da etnomatemática, ou seja, embora o trabalho tenha sido com a resolução-exploração de problema, no domínio prisional pode aparecer uma matemática que considere a palavra ou a pergunta dialogada, nessa pesquisa pudemos identificar esse fato, contudo, deixemos para outro momento essa discussão.

\section{OS DIFERENTES DOMÍNIOS DE EXPERIÊNCIAS PROFISSIONAIS ASSO- CIADOS AO MODELO DE ENTRADA E A RESOLUÇÁO-EXPLORAÇÃO DE PROBLEMA}

Fomos percebendo a grande massa de assistidos que necessitam da concretização das políticas desenvolvidas pela defensoria. Os encarcerados são uma parte da populaçáo que precisa da assistência (estadual, federal), assim, ao olhar pela ótica educacional, relemos a educação de jovens e adultos, nesse caso, dentro dos presídios.

Pensamos em desenvolver a pesquisa em uma escola regular e não em um presídio, e essa ideia persistia. Mas, à medida que fomos tendo acesso às informaçóes acerca dos presídios brasileiros, superamos possíveis dúvidas quanto ao campo.

11 D’AMBRÓSIO, A. História da Matemática: questóes historiográficas e políticas e reflexos na educação matemática, 1999.

12 Ibidem. 
Precisávamos ver sentido em desenvolver uma pesquisa ligada não apenas ao mundo acadêmico, porque sentimos a necessidade de associar a atividade na universidade às do trabalho em órgãos públicos.

Ao pensar na Defensoria, concebemos que a pesquisa pode contribuir enquanto meio de pensar uma parceria com o presídio, articulando açōes com a pastoral carcerária, verificando os atendimentos prestados dentro dos presídios.

No caso do INEP, o exame realizado anualmente, ENEM prisional, é uma política de onde se pode partir, seja para um trabalho de análise do alcance desses exames (limitaçóes e/ou avanços) ou mesmo apontar outros caminhos à uma educação com maior leque de açáo em que a família, por exemplo, esteja presente e sirva de suporte à educaçáo entre os próprios presos.

A pesquisa naárea deeducação matemática na Universidade Estadual da Paraíba (UEPB) por si só demostra a presença da universidade. Assim, portanto, o sentido da pesquisa envolvendo diferentes cotidianos, tendo como foco uma metodologia especifica, nos apareceu quando as experiências profissionais e vivências no âmbito universitário foram nos levando a pensar em uma liga, pela narrativa, que possibilitasse o deslocamento pelos domínios citados.

A narrativa enquanto suporte fortaleceu a elaboração de um modelo simplificado na figura 02. Isso possibilitou maior clareza durante os deslocamentos entre domínios, condiçáo que contribuiu com a aplicação da metodologia resolução-exploração de problemas, pois precisamos olhar os deslocamentos por diferentes cotidianos de modo simples.

Como pode ser visto, na figura 02, o modelo é bastante simples, e consta de duas circunferências que representam domínios externos e internos ao presídio. Com um modelo básico e simplificado associado à escrita narrativa, fomos fortalecendo a ideia de ver a sala de aula prisional inserida em um contexto mais amplo. Mas voltemos a outros elementos da pesquisa.

Chamamos a atenção ao transtorno de pessoas em conflito com a lei e, nesse momento, também como esforço de ligaçôes entre áreas de conhecimentos, encontramos o trabalho dissertativo de Padovani ${ }^{13}$ que relaciona o termo resoluçáo de problema, vendo-o como técnica e enquanto suporte à pesquisa com adolescentes em conflito com a lei.

13 PADOVANI, R. C. da. Resoluçáo de Problemas com Adolescentes em Conflitos com a Lei: Uma Proposta de Intervenção, 2003, p. 29-31. 
A técnica aplicada na pesquisa se liga a processos cognitivos de habilidades, como saber confrontar-se com um problema, e articular passos durante sua resolução. $\mathrm{O}$ termo problema, naquela dissertação, se encontra relacionado a uma situação ou conjunto de situaçóes bases às respostas dos pesquisados.

Procuramos pensar em fortalecer o trabalho com a exploração de problema. Contudo, percebi a dificuldade da área em definir o termo problema. Resgatamos o trecho da pesquisa que indica essa percepção:

\begin{abstract}
A leitura das unidades narrativas associada aos referenciais adotados levou a uma percepção das possibilidades do uso do termo Problema. Porém, isso só foi possível com certo amadurecimento do termo Exploração, porque tal amadurecimento ocorreu antes, durante, depois da experiência em sala de aula prisional. Entáo foi preciso perceber o termo Problema com certa relatividade de campo de conhecimento. Assim, a pesquisa mostra que a metodologia aplicada pode contribuir com desenvolvimento em diferentes áreas do conhecimento, uma vez que a leitura daquele termo central ocorre de maneira a se deslocar por diferentes áreas emergidas durante um diálogo em sala de aula. ${ }^{14}$
\end{abstract}

Esse caminho de procura por ligaçôes que apresente coerência do pensamento é uma atividade que exige paciência, especialmente quando se é preciso colher informaçóes de campos de conhecimentos ainda não trilhados. Nesta pesquisa precisamos olhar a educação em prisões de modo a reter certo panorama que permitisse ver o contexto da pesquisa como parte de um processo global. No tópico a seguir, apresento alguns recortes de pesquisas da área de Educação em Prisóes. Procuramos relacionar as leituras dessa área às experiências durante o período em sala de aula prisional.

\title{
3. APROXIMAÇÓES DA NARRATIVA EM EDUCAÇÁO MATEMÁTI- CA ÀS REFERÊNCIAS EM DIREITO E EDUCAÇÁO EM PRESÍDIOS
}

No primeiro tópico desse artigo, falamos da importância de dois construtos de autores que fortaleceram a ideia de desenvolver a pesquisa em sala de aula prisional. As obras citadas naquele tópico trazem as densidades de cada pesquisa presente nelas, contudo, aqui, procuramos partir da experiência narrada para, dela, considerar os recortes das pesquisas presentes nos construtos indicados.

$\overline{14}$ SANTOS, M. B. de. Educaçáo matemática com educandos privados de liberdade [manuscrito]: um trabalho com a metodologia resolução e exploração de problemas, 2016, p. 49. 
A experiência narrada aparece em toda escrita da pesquisa, as unidades narrativas são uma particularidade porque foi preciso maior aprofundamento com a metodologia aplicada em sala de aula.

Antes de apontar recortes das obras citadas acima, destacamos um momento significativo ocorrido durante debate promovido pela Universidade Estadual da Paraíba, quando ouvimos dois palestrantes da área de educação em presídios: Roberto Silva e Timothy Ireland. $\mathrm{Na}$ ocasiāo, foi abordado o "Direito à Educação" perpassando desde a Declaração Universal de Direitos Humanos às conferências internacionais; as garantias internacionais do direito à educação para pessoas privadas de liberdade no encontro de Hamburgo (1997) e na Conferência Internacional de Educação de Jovens e Adultos-Confintea VI, em Belém; Constituição Federal, 1988, artigo 208, que trata da Educação de Jovens e Adultos; Lei $\mathrm{n}^{\circ}$. 9394/96 que destaca a necessidade de atender os jovens em seu período de formação; Parecer CNE/CEB 4/2010 que trata da educação de jovens e adultos em cárcere enquanto direito humano subjetivo.

Tangenciamos o direito subjetivo ao encontrar em JR ${ }^{15}$ os três elementos: sujeito, um objeto e uma relação jurídica, na ordem, o titular do direito, o objeto que pode ser coisa, a própria pessoa ou outras pessoas, e uma relação jurídica entre pessoas.

Acompanhamos a exposição dos pesquisadores e percebemos um panorama de dados apresentado no tópico: "Crise da EJA no Brasil: sujeitos visíveis e invisíveis da EJA". ${ }^{16}$ Esse aspecto quantitativo possibilitou entrada em sala de aula prisional com uma visão mais ampla da situação.

Percebemos o particular desse quadro geral pela fala de outro professor, Roberto Silva, que, entre outros temas, tratou da "remiçãa ${ }^{17}$ da pena pelo estudo", que pode ser lido, também, no artigo intitulado: Por uma Política Nacional de Educação para os Regimes de Privação de Liberdade no Brasil. Nesse artigo o autor chama atenção à forma como o tema foi tratado no Congresso Nacional. Aponta o equívoco que é considerar a remição

\footnotetext{
15

FERRAZ JUNIOR, T. S. Introduçáo ao Estudo do Direito, 2008.

16 65,9 milhôes de pessoas com mais de 15 anos não frequentam a escola e não têm o Ensino Fundamental completo (Censo Demográfico/IBGE, 2010). 13,9 milhões de pessoas com 15 anos ou mais de idade, são consideradas analfabetas (Censo Demográfico/ IBGE, 2010). 4.046.169 pessoas com 15 anos ou mais de idade estão matriculadas na modalidade EJA (Censo Escolar/INEP 2010). 1,2 milhóes de pessoas com 15 anos ou mais de idade estão em turmas ativas de alfabetização (SBA/2011).

17 Roberto Silva faz um breve histórico sobre a remição em alguns países da América Latina e destaca o caso brasileiro: no Brasil a remição da pena é um instituto consagrado pela Lei Federal no 7210, de 1984, a Lei de Execução Penal (LEP) que a regulamenta em seu artigo 126.
} 
pelo trabalho como parâmetro à remição pelo estudo:

Essa omissão em relação aos estudos, pesquisas e diagnósticos, tanto por parte dos proponentes quanto das comissóes legislativas que precisam avaliar os diversos aspectos das proposiçōes, faz a remição pelo trabalho parecer um modelo ideal e bem sucedido, capaz de servir como parâmetro para remição pela Educação. ${ }^{18}$

No mesmo artigo, o autor olha as estruturas sociais das quais os jovens e adolescentes brasileiros são oriundos e aponta uma falência estrutural. Pois, entende que a profundidade da análise da questão penitenciária precisa considerar "a colonização, escravidão, a estrutura social, trabalho, educação, saúde...," ${ }^{19}$ para ele "Falharam a religião, a família, a escola, a comunidade, o mercado de trabalho, e a sociedade em geral em criar mecanismos de inclusão social que possibilitem assegurar o desenvolvimento contínuo e saudável de seus filhos." ${ }^{20}$

Nesse processo de pesquisa, ouvimos em 07 de novembro de 2014 dois outros pesquisadores da área de educação prisional: Marc de Maeyer e Hugo Rangel.

Encontramos em "educação para todos ao longo da vida" ${ }^{21}$ durante a escrita de nossa pesquisa narrativa necessidade de superar a relação tradicional. Vimos uma educação ao longo da vida enquanto emancipatória. "A educação ao longo da vida é, em si, uma educação libertadora; ferramenta que deve ser acessível a cada um, ela vai permitir compreender o porquê de se 'estar aqui no mundo', compreender seu mundo e sua representação de mundo."22

Ao referir-se à educação em prisōes, o autor acima diz:

No que se refere à educação na prisão, os programas educacionais deverão, portanto, privilegiar mais um trabalho sobre este "estar aqui no mundo" do que um aprendizado de técnicas e competências; veremos também que esta aprendizagem de técnicas e de competências, com certeza necessária, somente será possível se for precedida

$\overline{18}$ SILVA, R. Por uma Política Nacional de Educaçáo para os Regimes de Privaçáo de Liberdade no Brasil. In: LOURENÇO, A. S. da. e ONOFRE, E. M. C. (Orgs). O espaço da prisão e suas práticas educativas: enfoques e perspectivas contemporâneas, 2012, p.88.

$19 \quad$ Ibidem. p. 104.

$20 \quad$ Ibidem. p. 104.

21 MAEYER, M. de. Ter tempo não basta para que alguém se decida a aprender. Revista "Em Aberto", 2011, p. 44.

22

Ibidem. 
do questionamento sobre este estar aqui no mundo e com ele! $!^{23}$

Com relação ao conflito com a lei o autor lembra que este se estende à gestão política, posto que, uma vez negado outros direitos (educação, alimentação, saúde etc.), o agente público confronta-se com a legislação que estabelece a privação de liberdade. O conflito é entendido:

\begin{abstract}
'quando falamos de pessoas em conflito com a lei, constatamos também que os responsáveis pela gestão política estão eles próprios em conflito com suas próprias leis: não cumprem suas obrigaçóes que determinam que as necessidades elementares (alimentação, segurança, educação, saúde...) são um direito inalienável de todos! No entanto, mesmo nas sociedades democráticas, isto não acontece para todo o mundo' 24
\end{abstract}

Por outro lado, Lucena na revista Em Aberto escreveu "[...] hay que asegurarse que las actividades educativas sean dinámicas y puedan asi despertar el interes genuino de los reclusos." 25 Para tanto, a atuação de educadores precisa ser pensada e, no caso desta pesquisa, em particular, pensamos a atuação ao considerar diferentes cotidianos e particularizamos a sala de aula trabalhando com a metodologia resolução e exploração de problemas.

Percebemos, no contato com as pesquisas indicadas, a possibilidade de aproximação com trabalhos desenvolvidos na área de exploração e resolução problema. Desse modo ,destacamos as ideias de que apontam a codificação e a descodificação como movimentos "quase simultâneos" 26 do processo de entendimento de um problema. A metodologia, portanto, pode ser um forte apoio às práticas educativas de domínios prisionais.

Em outro artigo, percebemos o "estar aqui no mundo", ${ }^{27}$ de Freire, e entendemos como base a que os educandos não se reduzam a objeto de pesquisa, mas sejam ativos em sua voz, condição que, embora limitada, evidenciou-se, nesta pesquisa, em alguns momentos superação da cilada. In: LOURENÇO, A. S. da. e ONOFRE, E. M. C. (Orgs). O espaço da prisáo e suas práticas educativas: enfoques e perspectivas contemporâneas, 2012.
} 
quando nos referimos, nas unidades narrativas, aos "problemas prontos. ${ }^{28} \mathrm{~A}$ seguir resgato nossa escrita sobre essa questão de problemas prontos:

Os 'problemas prontos' levados à sala foram uma limitação da atividade educativa, posto que escolhidos por mim. Essa condiçáo, contudo, por vezes, foi superada, quando os problemas surgiram da condiçáo cotidiana em que o fazer matemático se revelou (...). Por outro lado, mesmo com essa percepção de limitação, a exploração em diferentes casos, algo comentado nas unidades narrativas, se distanciou da 'coisa' pronta. Então a concepção metodológica, durante a exploração, permitiu, em algumas situaçóes, o descolamento do item, mesmo discutindo os conteúdos presentes nele. Mas se a proposta estivesse descolada do exame possivelmente a matemática também seria mais criativa. ${ }^{29}$

A metodologia resolução-exploração de problema, interligada a uma base narrativa, permitiu perceber, embora tivesse conduzindo o trabalho em sala de aula através de problemas prontos, que a limitação por vezes foi superada, ou seja, o fazer matemático da rigidez do planejamento. Então, um diálogo pode ser muito mais rico caso o professor consiga conduzir, mesmo tendo seus problemas prontos, com abertura a construção de conhecimentos.

\section{CONSIDERAÇÓES FINAIS}

Ao olhar uma condição mais generalizante, em nossa pesquisa, entendemos que as populações de jovens, adultos, idosos, pessoas do campo, quilombolas, negros, índios, populações ribeirinhas e pessoas privadas de liberdade se aproximam da educaçáo de jovens e adultos. Contudo, foi preciso particularizar o estudo sem perder de vista aqueles outros domínios. Com esse esforço, nos inclinamos à pesquisa com educandos privados de liberdade.

Nesse processo de pensamento, fomos reforçando a ideia de uma educação matemática enquanto ciência social e a etnomatemática enquanto programa que fundamenta matemáticas em diferentes domínios e fortalece olhares diversos como diversas são as

28 DOMITE, M. C. M. do. Problematizaçáo: um caminho a ser percorrido em Educação Matemática, 1993.

29 SANTOS, M. B. de. Educaçáo matemática com educandos privados de liberdade [manuscrito]: um trabalho com a metodologia resolução e exploração de problemas, 2016, p. 54. 
populações assistidas pela Defensoria Pública União.

Percebemos a população de assistidos e as atividades laborais do cotidiano do trabalho, e entendemos que um amplo campo de pesquisa pode fundamentar-se com base na educação matemática de modo a subsidiar argumentos dos quais o próprio direito pode fazer uso como também captar novas compreensóes das populaçóes de assistidos.

\section{REFERÊNCIAS}

ANDRADE, S. de. Ensino - Aprendizagem de Matemática via resoluçáo, exploração, codificação e descodificação de problemas e a multicontextualidade da sala de aula. Rio Claro. IGCE, Unesp, 1998.

BOSON, E. P. A Defensoria Pública como Instituição articuladora do direito como padrão de reconhecimento. Revista da Defensoria Pública da Uniáo. Brasília, 2013.

COGOY, D. M. Assistência jurídica e judiciária no Brasil: Legitimação, eficácia e desafios do modelo brasileiro. Revista da Defensoria Pública da União. Brasília, 2012.

D’AMBRÓSIO, A. História da Matemática: questóes historiográficas e políticas e reflexos na educação matemática. São Paulo: UNESP, 1999.

DEFENSORIA PÚBLICA DA UNIÃO. Direitos previdenciários e assistências. Cartilha de orientação jurídica. 1.ed. Brasília: DPU, 2014 p.7

DOMITE, M. C. M. do. Problematização: um caminho a ser percorrido em Educação Matemática. Universidade Estadual de Campinas. São Paulo, 1993.

FERRAZ JUNIOR, T. S. Introdução ao Estudo do Direito. 6.ed. São Paulo: Atlas, 2008.

LUCENA, H. H. de. Educação em prisões na América Latina: elementos de análise. Revista “Em Aberto”. Brasília, 2011.

MAEYER, M. de. Ter tempo não basta para que alguém se decida a aprender. Revista “Em Aberto”. Brasília, 2011. 
MINISTÉRIO DA SAUUDE. Serviço de Avaliação de Medidas Terapêuticas Aplicáveis à Pessoa com Transtorno Mental em Conflito com a Lei, 2014.

SANTOS, G. A. As cotas como projeto de multiculturalismo. In: .Reconhecimento, utopia, distopia: os sentidos das políticas das cotas raciais. São Paulo: Annblume/FAPESP, 2012.

SANTOS, M. B. de. Educaçáo matemática com educandos privados de liberdade [manuscrito]: um trabalho com a metodologia resoluçáo e exploraçáo de problemas. Campina Grande. UEPB, 2016.

ONOFRE, E. M. C. Educação escolar na prisão: Controvérsias e caminhos de enfrentamento e superação da cilada. In: LOURENÇO, A. S. da. e ONOFRE, E. M. C. (Orgs). O espaço da prisão e suas práticas educativas: enfoques e perspectivas contemporâneas. São Carlos: EdUFSCar, 2012.

SILVA, R. Por uma Política Nacional de Educação para os Regimes de Privação de Liberdade no Brasil. In: LOURENÇO, A. S. da. e ONOFRE, E. M. C. (Orgs). O espaço da prisáo e suas práticas educativas: enfoques e perspectivas contemporâneas. São Carlos: EdUFSCar, 2012.

PADOVANI, R. C. da. Resoluçáo de Problemas com Adolescentes em Conflitos com a Lei: Uma Proposta de Intervençáo. São Carlos: UFSCar, 2003.

ONUCHIC, L. de la R. A Resolução de problemas na educaçáo matemática: onde estamos e para onde iremos? IV Jornada Nacional de Educação Matemática. Universidade de Passo Fundo, maio, 2012. 
Figura 01 - Representação do público assistido pela DPU

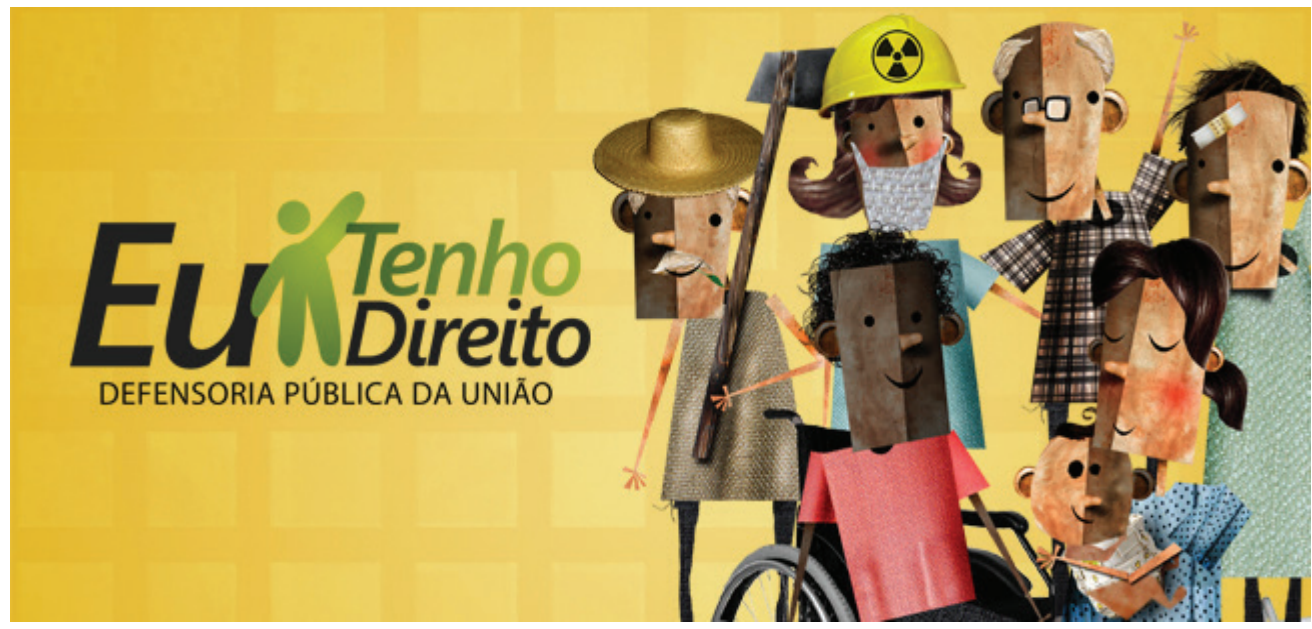

Fonte: Cartilha de orientação jurídica/Defensoria pública da União

Figura 02 - Modelo de entrada



Fonte: SANTOS, M. de B. Educação matemática com educandos privados de liberdade [manuscrito]: um trabalho com a metodologia resolução e exploração de problemas. Campina Grande. UEPB - 2016, p. 66. 